\title{
Establishing and Interpreting Graded Sonic Hedgehog Signaling during Vertebrate Neural Tube Patterning: The Role of Negative Feedback
}

\author{
Vanessa Ribes and James Briscoe \\ Developmental Neurobiology, National Institute for Medical Research, The Ridgeway, Mill Hill, \\ London, United Kingdom, NW7 1AA \\ Correspondence: james.briscoe@nimr.mrc.ac.uk
}

The secreted protein Sonic Hedgehog $(\mathrm{SHH})$ acts in graded fashion to pattern the dorsal-ventral axis of the vertebrate neural tube. This is a dynamic process in which increasing concentrations and durations of exposure to $\mathrm{SHH}$ generate neurons with successively more ventral identities. Interactions between the receiving cells and the graded signal underpin the mechanism of $\mathrm{SHH}$ action. In particular, negative feedback, involving proteins transcriptionally induced or repressed by $\mathrm{SHH}$ signaling, plays an essential role in shaping the graded readout. On one hand, negative feedback controls, in a noncell-autonomous manner, the distribution of $\mathrm{SHH}$ across the field of receiving cells. On the other, it acts cell-autonomously to convert different concentrations of $\mathrm{SHH}$ into distinct durations of intracellular signal transduction. Together, these mechanisms exemplify a strategy for morphogen interpretation, which we have termed temporal adaptation that relies on the continuous processing and refinement of the cellular response to the graded signal.

Fundamental to embryonic development is F the establishment of accurate and reliable patterns of gene expression and cellular differentiation in forming tissues. This usually takes place in a progressive manner resulting in a gradual emergence of the spatial profiles of gene expression. The deployment of morphogens to direct this process raises the question of how cells respond to a graded signal to acquire the appropriate spatial and temporal identity for their position. This question is further emphasized by studies indicating that the duration of exposure as well as the concentration of the morphogen determines the cellular response (Harfe et al. 2004; Pages and Kerridge 2000), and data revealing that the accuracy of patterning often appears greater than can be accounted for by the precision of the morphogen distribution (Bergmann et al. 2007; Bergmann et al. 2008; Bollenbach et al. 2008; Gregor et al. 2007; Houchmandzadeh et al. 2002; Jaeger et al. 2004). Whether the mechanism of the response of cells to a morphogen explains the temporal features, the precision and the reliability of tissue patterning needs to be addressed.

A realization is that, in many systems, an active molecular dialogue between the graded

Editors: James Briscoe, Peter Lawrence, and Jean-Paul Vincent

Additional Perspectives on Generation and Interpretation of Morphogen Gradients available at www.cshperspectives.org

Copyright (C) 2009 Cold Spring Harbor Laboratory Press; all rights reserved; doi: 10.1101/cshperspect.a002014

Cite this article as Cold Spring Harb Perspect Biol 2009;1:a002014 
signal and the target cells takes place. Both computational modeling and molecular genetics have suggested that this interchange is required for the interpretation of the graded signal and the spatial and temporal precision of the gene expression profiles set by morphogens (Ben-Zvi et al. 2008; Jaeger et al. 2004). Moreover, the interactions allow target cells to adjust their intracellular response to the signal and to shape the gradient itself (Ashe and Briscoe 2006; Freeman 2000; Gurdon and Bourillot 2001; Ibanes and Belmonte 2008; Jaeger et al. 2008; Pages and Kerridge 2000). In this view, the patterning action of morphogens is a dynamic process constantly refined by its interpretation. Here, we illustrate this concept using, as an example, the activity of the secreted protein sonic hedgehog $(\mathrm{SHH})$ during the specification of vertebrate spinal neurons. We will discuss how negative feedback, involving proteins transcriptionally regulated by $\mathrm{SHH}$, are essential for the appropriate response of cells to graded $\mathrm{SHH}$ signaling and to the progressive elaboration of discrete domains of neural progenitors. Moreover, by buffering the response of cells to fluctuations in the morphogen gradient, these mechanisms are likely to provide robustness and precision on pattern formation by the SHH gradient.

\section{NEURAL TUBE PATTERNING BY GRADED SONIC HEDGEHOG SIGNALING}

The vertebrate spinal cord displays a highly organized topology in which distinct neuronal subtypes are generated in characteristic order along the dorsoventral (DV) axis of the neural tube (Jessell 2000). The identity of these neurons is imposed by specific combinations of transcription factors (TFs) expressed in the progenitor cells from which the neurons derive (Guillemot 2007; Lupo et al. 2006; Zhuang and Sockanathan 2006) (Fig. 1). In the ventral spinal cord, graded SHH signaling regulates the expression of a subset of these TFs. Collectively, these define six pools of progenitors arrayed along the DV axis, termed floor plate (FP), p3, pMN, p2, p1, and p0 domains (Fig. 2A,B) (Briscoe et al. 2000;
Chiang et al. 1996; Ericson et al. 1996; Lei et al. 2006; Marti et al. 1995; Pierani et al. 1999; Vokes et al. 2007; Vokes et al. 2008; Wijgerde et al. 2002). These domains emerge in a progressive manner such that the expression of TFs characteristic of increasingly more ventral progenitor populations appear sequentially at the ventral midline of the neural tube (Jeong and McMahon 2005) (Fig. 2C). The order of appearance of the TFs corresponds with their requirement for increasing concentrations and durations of $\mathrm{SHH}$ signaling (Briscoe et al. 2000; Dessaud et al. 2007; Ericson et al. 1997). This is apparent from ex vivo experiments using explants of chick neural tissue, which showed that two- to threefold increases in the concentration of recombinant SHH sequentially switches the identity of cells towards a more ventral cell fate (Briscoe et al. 2000; Dessaud et al. 2007; Ericson et al. 1997; Roelink et al. 1995). Similarly, increasing the length of time for which cells are exposed to $\mathrm{SHH}$ directs the explants toward a more ventral identity (Dessaud et al. 2007; Ericson et al. 1996). These features are consistent with a morphogen mechanism of action and raise the question of how progenitor cells interpret the quantitative information encoded by the concentration and duration of exposure to SHH. Here, we will argue that this process is tightly coupled to transcriptional targets of SHH signaling that influence the graded readout of $\mathrm{SHH}$ signaling.

\section{A Temporal and Spatial Gradient of $\mathrm{SHH}$ Protein in the Neural Tube}

Attention has focused on visualizing and measuring the distribution of $\mathrm{SHH}$ protein in the neural tube. SHH protein is first secreted from the notochord (Echelard et al. 1993; Roelink et al. 1995). As this structure regresses, a second center of SHH production is set up within FP cells of the neural tube (Marti et al. 1995; Roelink et al. 1995). However, this source is only established after the molecular markers of the six ventral neural progenitor domains have been induced, suggesting that ventral patterning may rely primarily on $\mathrm{SHH}$ 
A
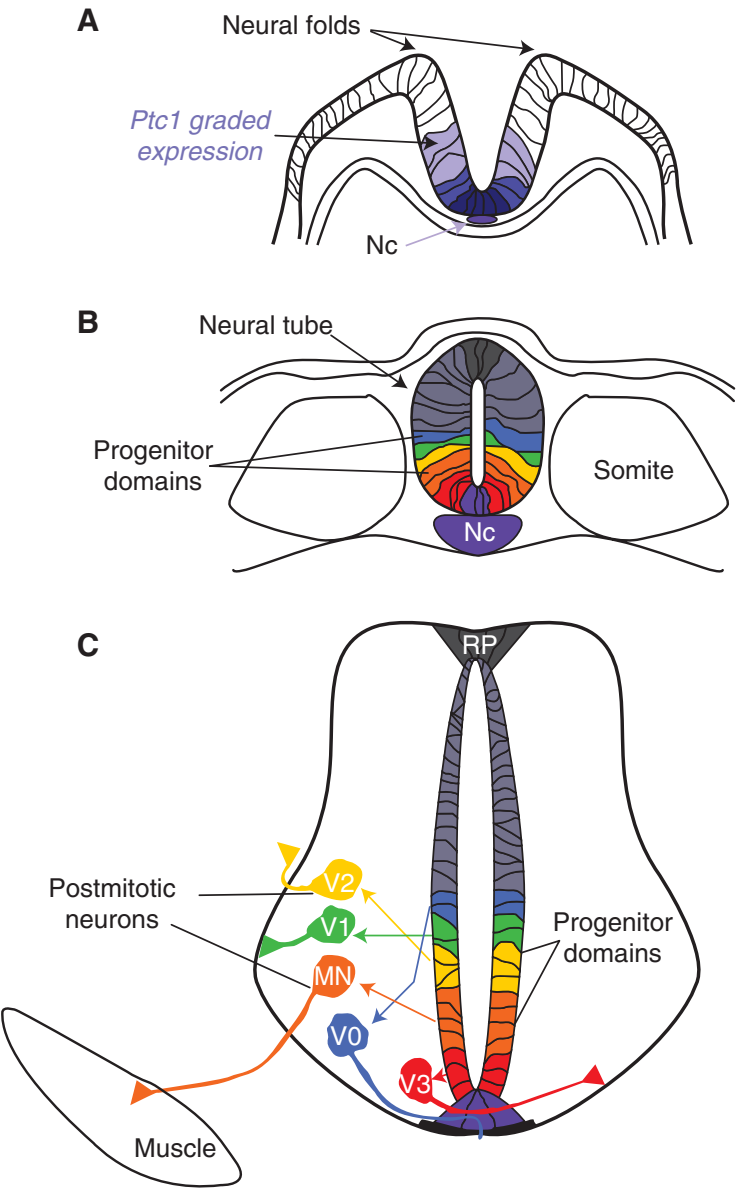

Figure 1. Establishment of the spatial organization of neurons from ventral progenitor cells of the spinal cord. (A) Graded expression of the receptor Ptcl (blue) in the folding neural plate, induced by SHH secreted from the Notochord. (B) After neural tube closure, six domains of progenitor cells, termed FP, p3, pMN, p2, p1, and p0 ( purple, red, orange, yellow, green, blue) are precisely arranged along the dorsal-ventral (DV) axis of the neural tube. $(C)$ Each progenitor domain generates a distinct subtype of interneurons (V0-V3) or motor neurons $(\mathrm{MN})$. These postmitotic cells reach their final settling positions within the spinal cord via stereotypic migration pathways. The extension of their axons along specific routes initiates the formation of functional circuits. (Nc) Notochord, (FP) floor plate.

derived from the notochord (Chamberlain et al. 2008; Jeong and McMahon 2005). Visualization of $\mathrm{SHH}$ protein in neural tissue has revealed its long range spread and indicated that most, if not all, progenitors in the ventral neural tube are exposed to $\mathrm{SHH}$ (Chamberlain et al. 2008; Gritli-Linde et al. 2001; Huang et al. 2007). Accordingly, inhibiting the response of cells to $\mathrm{SHH}$ located some distance from the ventral midline blocks their ability to generate ventral gene expression profiles and the associated differentiated cell types (Briscoe et al. 2001; Persson et al. 2002; Wijgerde et al. 2002).

The generation of a mouse $\mathrm{SHH}$ allele that encodes a biologically active $\mathrm{SHH}$ fused with the green fluorescent protein (SHH-GFP) has allowed a detailed assessment of the distribution and spread of the morphogen through the target field (Chamberlain et al. 2008). SHH-GFP molecules display punctate patterns of distribution within the neural tube. 
V. Ribes and J. Briscoe

A

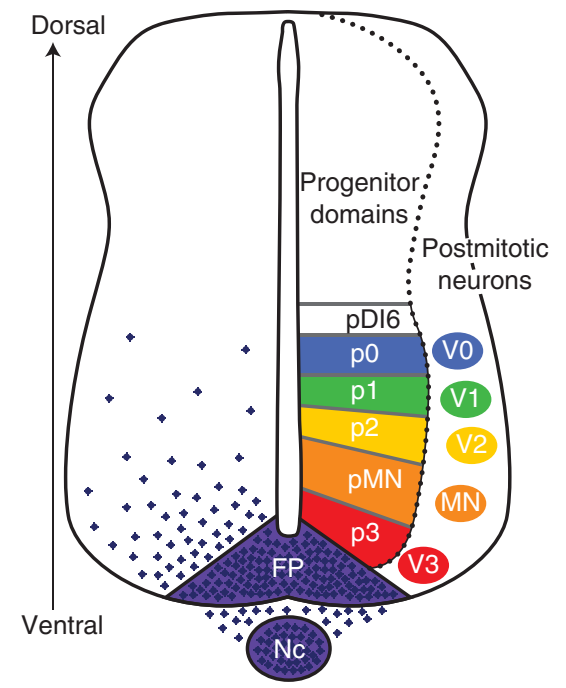

B Profiles of expression of TFs

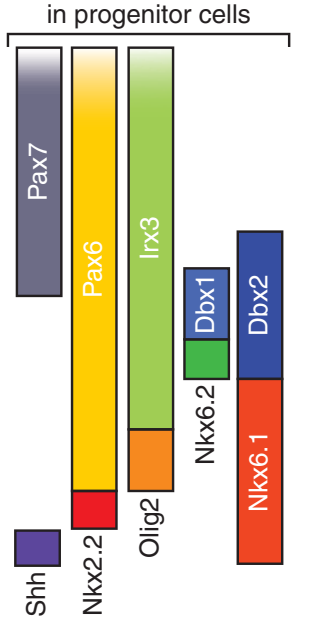

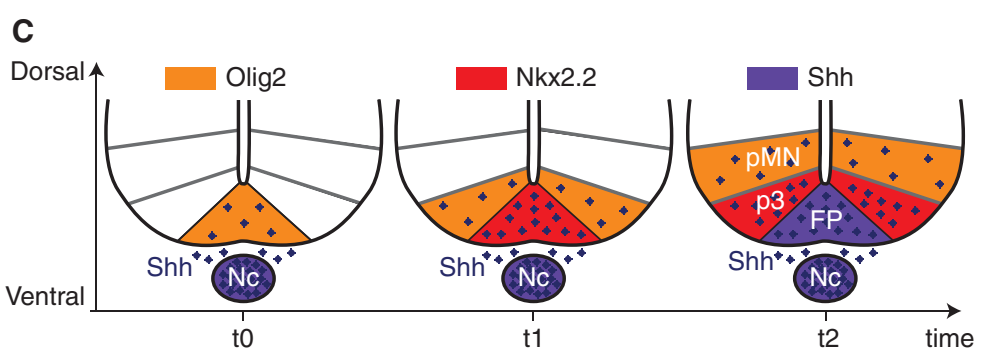

Figure 2. Progressive emergence of SHH-regulated gene expression profiles within progenitor cells defines neuronal subtype identities in the ventral spinal cord. (A) Arrayed along the dorsal-ventral (DV) axis of the ventral neural tube are six domains of progenitor cells, FP, p3, pMN, p2, p1, and p0, which generate V0-V3 and MN neuronal subtypes. The spatial organization of the progenitor domains is established by a gradient of SHH protein (purple) secreted from the Nc and FP. (B) The restricted expression profiles of the TFs Nkx2.2, Olig2, Nkx6.1, Nkx6.2, Dbx1, Dbx2, Irx3, Pax6, and Pax7 within progenitors is regulated by graded SHH signaling. Each progenitor domain expresses a unique combination of TFs. $(C)$ The TFs Olig2 and $\mathrm{Nkx} 2.2$, as well as $\mathrm{SHH}$ itself, distinguish the three most ventral progenitor domains ( $\mathrm{pMN}$, p3, and FP, respectively). The expression of each of these markers is initiated at successive developmental time points within the midline of the neural tube and extends to more dorsal positions with the appearance of the next marker at the midline. This series of gene induction events occurs in parallel to the accumulation and extension of the gradient of SHH protein in the ventral neural tube. (Nc) Notochord, (FP) floor plate.

Intriguingly, these punctae seem to be enriched apically in progenitors and are found close to ciliary basal bodies. The functional significance of this association is unclear. Quantification of the distribution of this fusion protein reveals that the gradient of $\mathrm{SHH}$ protein decays exponentially along the DV axis (Chamberlain et al. 2008) (see Fig. 5B). As expected, the most ventral progenitor cells, the FP and p3 domain, are exposed to the highest levels of ligand. Decreased ligand levels are observed across the $\mathrm{MN}$ progenitor domain and the levels drop below detectability within the p2 progenitor domain.

The amplitude of the SHH-GFP gradient increases as neural tube development progresses (Chamberlain et al. 2008). As a consequence, cells close to the ventral midline are exposed to higher concentrations of $\mathrm{SHH}$ and for a longer period of time than more dorsal cells. 
Significantly, this matches the progressive induction of genes that require increasing levels or durations of $\mathrm{SHH}$ signaling at the ventral midline of the neural tube (Jeong and McMahon 2005; Dessaud et al. 2007) (Figs. 2C and 6A). For example, the expression of Olig2, a determinant of $\mathrm{MN}$ identity, is initially observed in ventral midline cells at a time when these cells have been exposed to a low concentration of $\mathrm{SHH}$ for a short period of time (Chamberlain et al. 2008; Jeong and McMahon 2005) (Fig. 2C). Olig2 expression expands rapidly to more dorsal positions as the gradient of $\mathrm{SHH}$ extends dorsally. Concomitant with this, the level of $\mathrm{SHH}$ protein increases at the midline, hence these cells switch off Olig2 and induce $\mathrm{Nkx} 2.2$, a progenitor marker located ventral to the $\mathrm{MN}$ progenitor domain.

A detailed analysis of $\mathrm{SHH}$ distribution once the TF combinations defining the ventral progenitor domains have been set up is not yet available. Nevertheless, it is apparent that it varies during time (Chamberlain et al. 2008; Danesin et al. 2006). Thus, the SHH gradient within the ventral spinal cord appears to be continually and actively modified over the course of development. The functional relevance of the dynamic nature of the $\mathrm{SHH}$ gradient is suggested by the close correlation between the amount and time of $\mathrm{SHH}$ exposure required to generate differential expression profiles in vitro and the timing and spatial patterns of gene induction in the neural tube.

The spread of SHH through the neural tube and the accuracy of its distribution are likely to be a function of the tight regulation of its secretion, diffusion, retention, and degradation by the combined action of multiple proteins (Dessaud et al. 2008; Ingham and McMahon 2001; Varjosalo and Taipale 2008). Before secretion, $\mathrm{SHH}$ is cholesterol-modified at the carboxyl terminus and palmitoylated at the amino terminus and then assembled into a high-molecular-weight complex (Varjosalo and Taipale 2008). The presence of lipid moieties and formation of the high-molecularweight complex affects the diffusivity of $\mathrm{SHH}$ (Zeng et al. 2001). In addition, the spread of
SHH is influenced by the expression of extracellular and transmembrane proteins that bind to $\mathrm{SHH}$ and alter its rate of diffusion or degradation within the target field. Heparan sulfate proteoglycans (HSPGs), components of the extracellular matrix, bind $\mathrm{SHH}$ and are likely to contribute to the rate of spread of $\mathrm{SHH}$ through the neural tube (Rubin et al. 2002). Similarly, the extracellular protein You/ Scube2, a positive regulator of SHH signaling, might act by facilitating transport or stabilizing $\mathrm{SHH}$ protein within the extracellular matrix (Woods and Talbot 2005). Besides these SHH binding proteins, which are uniformly present in the neural tube, other factors affecting the spread of SHH display restricted expression patterns. The expression of several of these, including the SHH-receptor Patched 1 (Ptc1), Hedgehog interacting protein (Hhip1), and the proteins Cdo, Boc, and Gas1, is regulated by $\mathrm{SHH}$ signaling itself (Allen et al. 2007; Chuang et al. 2003; Goodrich et al. 1996; Goodrich et al. 1997; Jeong and McMahon 2005; Marigo and Tabin 1996; Martinelli and Fan 2007; Tenzen et al. 2006; Yao et al. 2006; Zhang et al. 2006). Thus, neural cells express many extracellular modulators of $\mathrm{SHH}$ and the expression of a subset of these is controlled by $\mathrm{SHH}$ signaling. In the following section, we will discuss the function and significance of the $\mathrm{SHH}$ regulated subset on the establishment and interpretation of a graded signal.

\section{Regulation of Gli Activity by SHH Signaling is Required for the Graded Response}

Two transmembrane proteins mediate the intracellular transmission of a SHH signal, Patched1 (Ptc1), which binds to $\mathrm{SHH}$, and the seven-pass transmembrane protein Smoothened (Smo) (Dessaud et al. 2008; Ingham and McMahon 2001; Varjosalo and Taipale 2008) (Fig. 3). The binding of SHH to Ptcl relieves its inhibition of Smo, allowing intracellular signal transduction. Several lines of evidence suggest that Smo activity is necessary and sufficient for transduction of a graded $\mathrm{SHH}$ signal in receiving cells. First, the spinal cord of Smo $-/-$ mouse embryos lacks all cell fates 


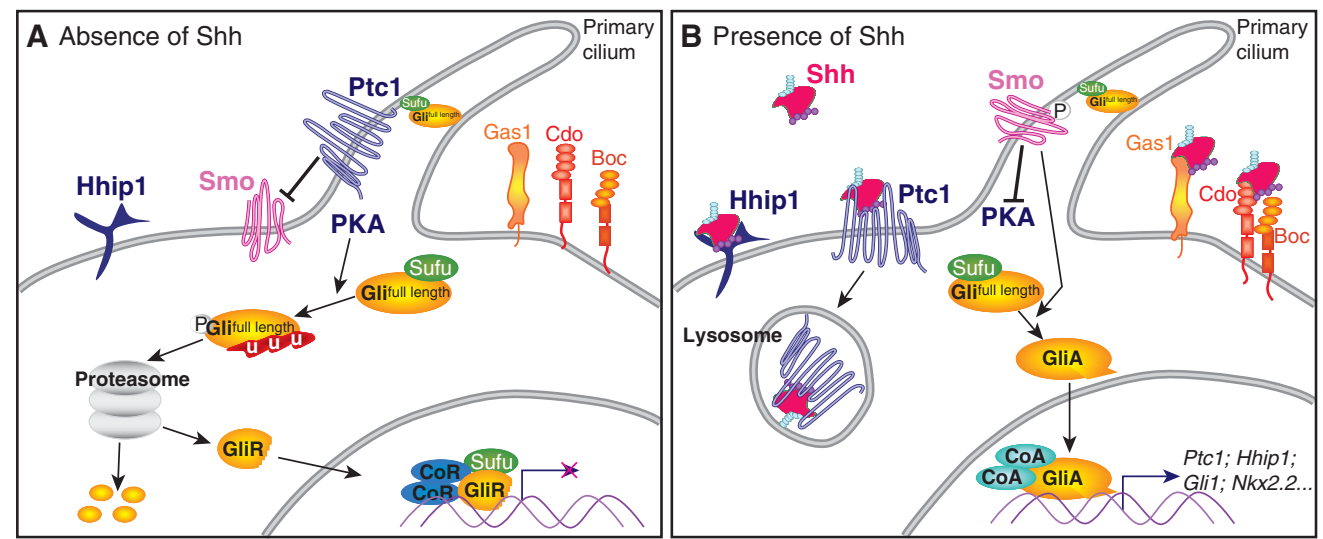

Figure 3. SHH signal transduction. (A) In the absence of SHH, the receptor Ptcl represses the activity of the transmembrane protein Smo and the translocation of Smo to the primary cilium of the cell. In these cells, protein kinase A (PKA) promotes the proteasome-dependent partial processing or complete degradation of the Gli transcription factors (Gli2 and Gli3). The truncated forms of these proteins (GliR) translocate to the nucleus and repress the transcription of SHH signaling targets. SuFu maintains any remaining full-length Gli proteins in an inactive state. (B) The binding of SHH to Ptcl releases repression of Smo, allowing its translocation into the cell's cilium. The activation of Smo inhibits the proteolytic processing of Gli proteins and culminates in activated Gli proteins (GliA) translocating to the nucleus to activate target gene expression. At the cell surface, in addition to Ptc1, the SHH-binding membrane protein Hhip1 binds SHH and inhibits signaling. Conversely, the SHH-binding proteins Gas1, Cdo, and Boc enhance the response of cells to the morphogen.

normally generated ventral to the $\mathrm{p} 1$ progenitor domain (Wijgerde et al. 2002; Zhang et al. 2001). Second, a dominant active form of Smo is sufficient to induce, in a cell-autonomous manner, gene expression and cellular differentiation programs characteristic of the ventral neural tube (Hynes et al. 2000). Third, small molecule agonists and antagonists that directly bind and activate or inhibit Smo, independently of Ptcl activity, are able to recapitulate the effect of a SHH concentration gradient on the expression of ventral markers in vitro (Dessaud et al. 2007). Thus, graded activation of Smo mimics the graded response produced by different concentrations of $\mathrm{SHH}$, indicating that Smo activity is sufficient to explain the graded response of neural cells to $\mathrm{SHH}$.

The molecular cascade acting downstream of Smo activation remains poorly defined but it appears to depend on the primary cilium and the integrity of intraflagellar transport (Eggenschwiler and Anderson 2007). Ultimately, Smo activity regulates the activity of a family of zinc-finger-containing transcriptional effectors, the Gli proteins (Gli1, -2, and -3) (Matise and Joyner 1999) (Fig. 3), which are capable of acting both as activators (GliA) and repressors (GliR) of transcription. In the neural tube, the three Gli proteins together control the expression of SHH target genes (Jacob and Briscoe 2003; Vokes et al. 2007; Vokes et al. 2008).

In the absence of SHH, GliR activity is thought to dominate. This is a result of the degradation of Gli2 protein and the partial proteolytic processing of Gli3 into a truncated isoform, Gli3R, which functions as a transcriptional repressor (Aza-Blanc et al. 2000; Pan et al. 2006; Tempe et al. 2006; Wang et al. 2000) (Fig. 3A). Thus, in the neural tube, where SHH decreases below the threshold necessary to activate signaling, the transcriptional inhibitory activity of Gli3R is expected to govern responses. In line with this prediction, embryos with a mutation in Gli3 show a dorsal expansion of some markers of the ventral neural tube (Persson et al. 2002). This phenotype is rescued by an allele of Gli3 that encodes only the transcriptional repressor 
form of Gli3, demonstrating that the repressor activity of Gli3 is crucial for defining the dorsal extent of the ventral neural tube (Persson et al. 2002).

In cells responding to $\mathrm{SHH}$, the proteolytic processing of Gli3 is inhibited, resulting in a reduction in the levels of Gli3R. Consistent with this, the inactivation in embryos, of both $\mathrm{SHH}$ and Gli3, leads to a partial rescue of $\mathrm{SHH}$ null phenotype. The rescue includes the expression of markers characteristic of the $\mathrm{p} 1, \mathrm{p} 2$, and $\mathrm{pMN}$ domains (Persson et al. 2002). A similar result is also observed in embryos that are depleted for all three Gli proteins (Bai et al. 2004; Lei et al. 2004) and in embryos lacking both Smo and Gli3 (Wijgerde et al. 2002). These data indicate that the SHHdependent removal of Gli3 repressor activity is sufficient for the specification of p1, p2, and pMN cell identities. Nevertheless, in the compound mutants that lack SHH and Gli activity, an abnormal intermingling of the different progenitor identities is observed. This suggests that an input from the gradient of $\mathrm{SHH}$ is necessary for the accurate patterning and/or the positioning of these cell types.

The response to the highest levels of $\mathrm{SHH}$ signaling requires more than the removal of Gli3R activity. Notably, the most ventral cell identities, p3 and FP, require positive Gli transcription activity. In cells exposed to high $\mathrm{SHH}$ concentrations, Gli2 degradation ceases, resulting in the accumulation of the full length transcriptional activator isoform (Pan et al. 2006). In addition, the transcription of Gli3 is repressed and Gli1, which appears to act exclusively as an activator, is induced (Aza-Blanc et al. 2000; Dai et al. 1999; Lee et al. 1997; Marigo et al. 1996; Ruiz i Altaba 1998). Together, these events result in an increase in GliA activity, which might be boosted further by SHH-mediated posttranslational events that enhance the transcriptional activity of Gli1 and Gli2 (Barnfield et al. 2005; Merchant et al. 2004; Pan et al. 2006) (Fig. 3B). The loss of FP and p3 cells in mouse embryos lacking Gli2 emphasizes the importance of Gli2 in mediating the response to high levels of $\mathrm{SHH}$. This phenotype is exacerbated when the Gli1 locus is also disrupted (Ding et al. 1998; Matise et al. 1998; Park et al. 2000). Together, these studies lead to the attractive and simple idea that different levels of Gli activity mediate the graded response of cells to $\mathrm{SHH}$. In support of this, gain-of-function experiments indicate that changes in the transcriptional activity of GliA are sufficient to recapitulate the patterning activity of graded $\mathrm{SHH}$ signaling (Lei et al. 2004; Stamataki et al. 2005).

In addition to the level, the duration of Gli activity also appears to be an essential feature of how cells interpret graded SHH signaling (Dessaud et al. 2007; Stamataki et al. 2005). The length of time necessary for a dominant active form of Gli3 to induce ventral gene expression correlates with the DV position of expression of the gene in vivo (Stamataki et al. 2005). Accordingly, ventrally expressed genes take a longer time to be induced than genes expressed further away from the ventral midline (Dessaud et al. 2007; Stamataki et al. 2005). In this view, the sequential induction of more ventrally expressed genes is a consequence of a progressive increase in the duration and the level of Gli activity in response to the gradual augmentation in morphogen concentration.

\section{A Temporal Adaptation Mechanism Integrates the Duration and Concentration of SHH Signaling}

The mechanism of $\mathrm{SHH}$ signal transduction raises the question of how cells integrate temporal variations in $\mathrm{SHH}$ concentration to generate distinct quantities and durations of Gli activity. Ex vivo assays indicate that when exposed for short periods of time to either high or low concentrations of $\mathrm{SHH}$, cells generate similar levels of Gli activity and express the same sets of genes (Dessaud et al. 2007) (Fig. 6A). Over time, the levels of Gli activity in cells exposed to a constant amount of $\mathrm{SHH}$ decrease such that the rate of decrease is inversely proportional to $\mathrm{SHH}$ concentration (Fig. 6A). In other words, at early time points, relatively low concentrations of $\mathrm{SHH}$ are sufficient to activate the highest levels of signal transduction. With increasing time, however, cells become 
desensitized to ongoing $\mathrm{SHH}$ signaling. In this way, cells convert a concentration of SHH into a proportional period of Gli activity. The progressive increase in the length of these periods in response to higher $\mathrm{SHH}$ concentration correlates with the sequential appearance of more ventrally expressed genes (Dessaud et al. 2007; Jeong and McMahon 2005).

These data suggest a novel mechanism"temporal adaptation"-for how cells interpret a morphogen. In this model, extracellular concentrations of signal are converted into intracellular periods of signal transduction. One feature of this mechanism is that changing the concentration and/or the duration of $\mathrm{SHH}$ exposure has a similar effect on gene expression: Reducing either results in a decrease in the duration of intracellular Gli activity. Together with the evidence that increasing levels of Gli activity induce progressively more ventral responses, the data suggest that the induction of a particular DV identity requires Gli activity to be maintained above a specific level for a set period of time. This reconciles previous models of morphogen activity that have emphasized either concentration- or time-dependent mechanisms (Dessaud et al. 2008; Gurdon and Bourillot 2001; Harfe et al. 2004; Ibanes and Belmonte 2008; Pages and Kerridge 2000; Scherz et al. 2007). A temporal adaptation mechanism transforms both the duration and concentration of the extracellular ligand into corresponding durations and strength of intracellular signaling. Importantly, the way in which cells convert an extracellular concentration of $\mathrm{SHH}$ into different durations of intracellular Gli activity depends on negative feedback initiated by SHH-Gli signaling. We will discuss the function and implications of these regulatory loops in the next section.

\section{NEGATIVE FEEDBACK LOOPS INVOLVING SHH BINDING PROTEINS SHAPE THE GRADED READOUT OF SHH SIGNALING}

A diverse set of membrane-linked proteins influence the spread of $\mathrm{SHH}$ through the neural tube and the response of cells to this signal. These factors transcriptionally respond to $\mathrm{SHH}$ signaling and bind to $\mathrm{SHH}$ to either enhance or inhibit signal transduction. These proteins can be divided into two categories (Fig. 4). The first group comprises Cdo, Boc, and Gas1. These enhance signaling, but are transcriptionally down-regulated by $\mathrm{SHH}$ signaling (Allen et al. 2007; Martinelli and Fan 2007; Tenzen et al. 2006; Yao et al. 2006; Zhang et al. 2006). A second category acts as negative feedback regulators. It includes the receptor Ptcl and the EGF-repeat-containing membrane-linked protein Hhip1, both of which inhibit $\mathrm{SHH}$ signal transduction and are transcriptionally up-regulated by SHH signaling (Chuang et al. 2003; Goodrich et al. 1996; Goodrich et al. 1997; Jeong and McMahon 2005; Marigo and Tabin 1996). Together, these two sets of proteins constitute a regulatory feedback system that, as described below, is crucial for the morphogen activity of SHH in the neural tube and is likely to provide robustness and precision to pattern formation.

Feedback Loops Involving Gas1, Cdo, and Boc Initiate the Ventral Specification Program

The related transmembrane proteins Cdo and Boc, as well as the GPI-linked protein Gas1 enhance intracellular $\mathrm{SHH}$ signaling possibly by binding $\mathrm{SHH}$ and presenting it to Ptcl (Allen et al. 2007; Martinelli and Fan 2007; Tenzen et al. 2006; Yao et al. 2006; Zhang et al. 2006). During neural development, Gas1 is initially expressed within ventral progenitors of the spinal cord (Allen et al. 2007). Its expression in the ventral neural tube is then down-regulated and expression is observed in intermediate and dorsal positions. Cdo and Boc are mainly expressed within the intermediate and dorsal neural tube. The expression domain of Boc extends more ventrally than that of Cdo (Tenzen et al. 2006). In addition, Cdo is transiently expressed within presumptive FP cells at the ventral midline of the neural tube at early developmental stages. The repression of each of these genes in the ventral neural tube is likely to be a consequence of their negative regulation by $\mathrm{SHH}$ signaling (Allen et al. 2007; Tenzen et al. 2006). 


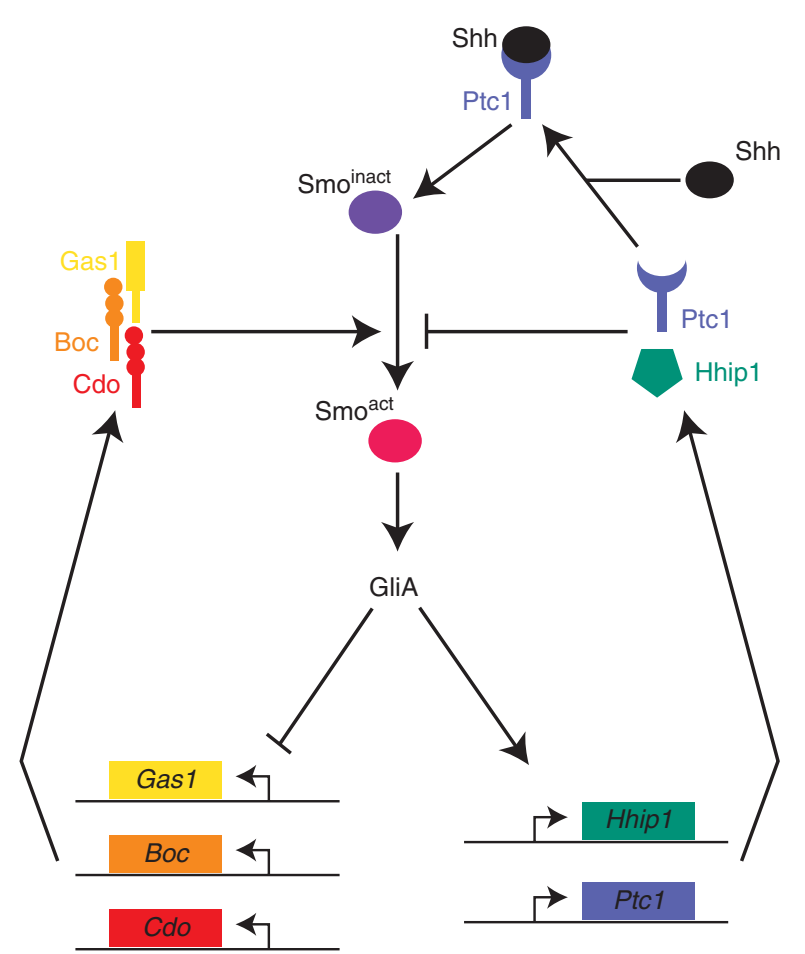

Figure 4. Negative feedback loops in the SHH signaling pathway driven by SHH-binding proteins. The membrane proteins Gas1, Cdo, and Boc promote the activation of Smo and are transcriptionally inhibited by SHH signaling. Conversely, Ptc1 and Hhip1 are transcriptionally induced by Gli activation and inhibit the transduction of a SHH signal to Smo.

Despite the transience of Cdo and Gas1 expression in the ventral neural tube, their function is essential for the appropriate specification of cellular identities in this region. Null mutations in Cdo or Gas1 result in neural tube phenotypes reminiscent of a decrease in SHH signaling (Fig. 5A). These are further exacerbated in Shh $+/-$ embryos (Allen et al. 2007; Martinelli and Fan 2007; Tenzen et al. 2006). Furthermore, the neural tube of Cdo-/-; Gas1 - / - double mutant embryos lack FP, p3, and pMN cells (Allen et al. 2007). Consistent with a positive function of these proteins on SHH signaling, forced expression of any of the three proteins in the chick neural tube promotes the cell-autonomous induction of more ventral cell fates (Allen et al. 2007; Martinelli and Fan 2007; Tenzen et al. 2006) (Fig. 5B). Together, these studies suggest that Gas1 and Cdo contribute to the generation of an early burst of SHH signaling in the ventral neural tube, perhaps by sensitizing cells to low levels of SHH protein that are presumably present at these times (Allen et al. 2007). The SHH dependent inhibition of Gas1 and Cdo expression ensures that this initial boost in signaling is only temporary. Likewise, the dorsal expression of the three proteins might provide a mechanism to enhance sensitivity to low levels of SHH in these regions.

Ptc1 and Hhip1 Feedback Loops Contribute at Multiple Levels to the Accurate Readout of Graded SHH Signaling

In contrast to the proteins described in the preceding section, Hhip1 and Ptcl are strong inhibitors of SHH signaling (Coulombe et al. 2004; Goodrich et al. 1996; Goodrich et al. 1997; Jeong and McMahon 2005; Ochi et al. 2006; Olsen et al. 2004; Taipale et al. 2002). In vivo, these factors share overlapping functions to 
V. Ribes and J. Briscoe

A
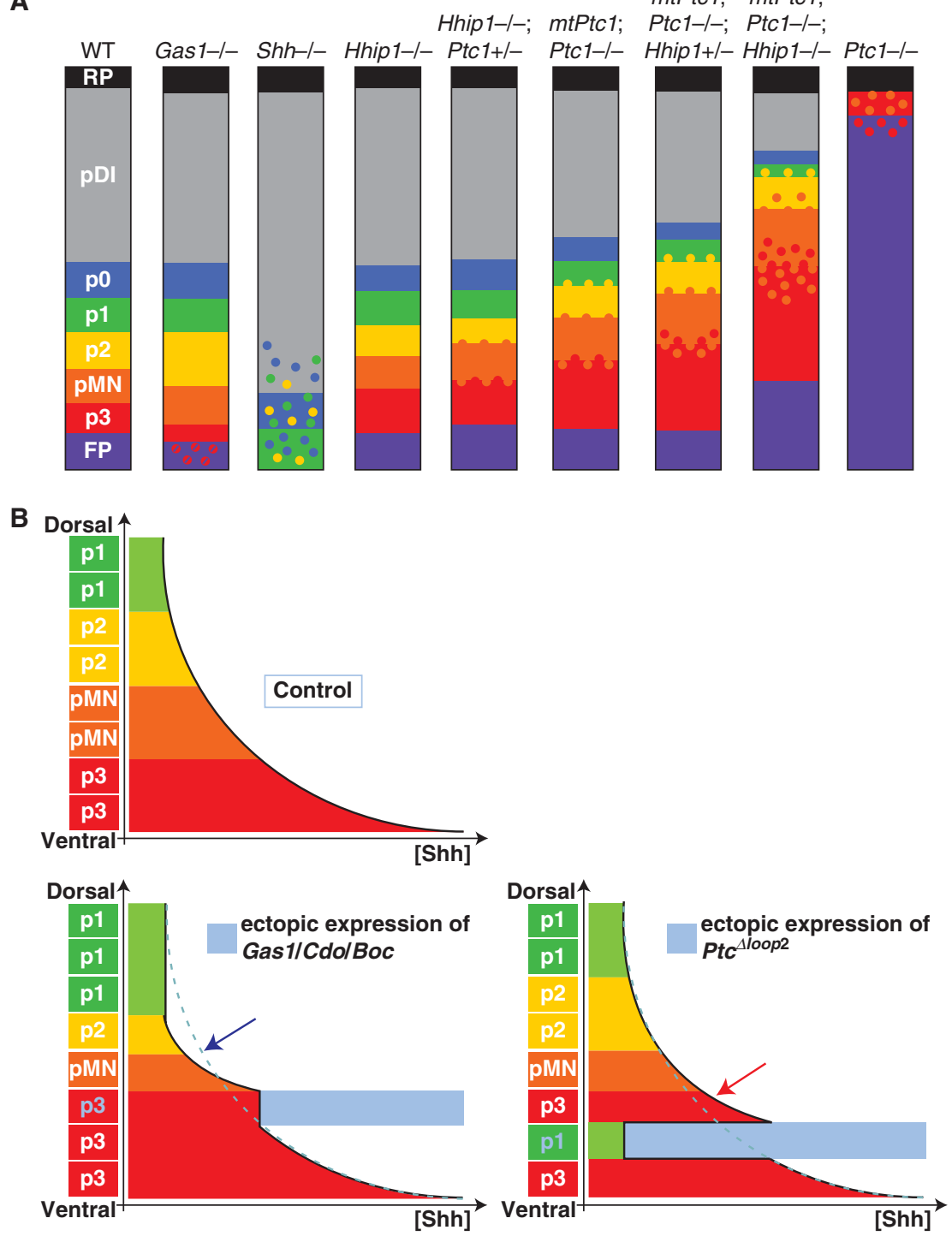

Figure 5. Regulation of SHH-mediated pattern formation in the ventral spinal cord by the SHH-binding proteins. (A) Diagrammatic representation of the effect of mutations of SHH binding proteins on pattern formation in the neural tube. $\mathrm{SHH}-/$ - spinal cord displays a complete absence of molecular identities characteristic of the FP, p3, and pMN progenitor domains and severe reduction and ventral displacement of p2, p1, and p0 identities. Loss of Gas1 (Gas1-/-) results in a reduction of the number of p3 cells, reminiscent of a mild reduction in the SHH signaling activity. In contrast to Gas1 and SHH mutant embryos, compound mutant embryos for Hhip1 and Ptc1 display expansion of the ventral most progenitor domains. In the Hhip 1 mutant, the p3 progenitor domain increases in size. The other ventral progenitor domains remain unaffected. More dramatically, in Ptc1 mutants, dorsal progenitor identities are absent, with the exception of the roof plate, and most progenitor cells adopt a FP identity. A few scattered cells with pMN and p3 characteristics are intermixed in the most dorsal regions. This phenotype is partially rescued by a transgene expressing Ptcl ubiquitously at low levels (MtPtc1). Thus, in the MtPtc1;Ptc1-/ the $\mathrm{p} 3, \mathrm{pMN}$ progenitor domains are expanding dorsally. Most strikingly, cells with distinct fates are mixed at the boundaries between the $\mathrm{p} 3$ and $\mathrm{pMN}$, and the $\mathrm{pMN}$ and the p2 progenitor domains in these compound mutants, indicating a role for Ptc1-mediated feedback in the precision of pattern formation. 
limit the extent and the level of SHH signaling in the target field. The complete elimination of Ptc1 expression results in derepression of $\mathrm{SHH}$ signaling throughout the neural tube and the induction of ventral identities along the entire DV axis (Goodrich et al. 1997) (Fig. 5A). This phenotype can be partially rescued by expressing ubiquitously low levels of Ptcl using a metallothionein promoter (Jeong and McMahon 2005; Milenkovic et al. 1999) (Fig. 5A). In these mtPtcl:Ptcl-/embryos, the progressive removal of Hhip1 alleles leads to a gradual dorsal expansion of gene expression and cell identities characteristic of the ventral neural tube (Fig. 5A). Conversely, ectopic expression of Hhip 1 or Ptc1 blocks, in a cell-autonomous manner, the establishment of ventral cell types in the neural tube (Briscoe et al. 2001; Stamataki et al. 2005).

A similar activity of Ptc is observed in Drosophila tissue patterned by $\mathrm{Hh}$ signaling (Chen and Struhl 1996). In this case, an alteration in the patterning of the surrounding tissue is also observed. This nonautonomous effect is attributable to the ability of Ptc to bind and sequester $\mathrm{Hh}$, thereby altering the local concentration of $\mathrm{Hh}$ and restricting its spread through the tissue (Chen and Struhl 1996). Several experiments support the idea that the activity of Ptc1 and Hhip1 and their regulation by $\mathrm{SHH}$ signaling play a similar role in shaping the extracellular gradient of $\mathrm{SHH}$ protein in the vertebrate neural tube. The forced expression of a form of Ptcl that does not bind $\mathrm{SHH}$ but retains the ability to inhibit $\mathrm{SHH}$ signal transduction $\left(\mathrm{Ptcl}^{\Delta \text { loop2}}\right)$ identified a noncell-autonomous role for Ptcl in restricting the dorsal expansion of ventral cell fates (Fig. 5B). This suggested that $\mathrm{SHH}$ dependent up-regulation of Ptc1, or other molecules capable of binding $\mathrm{SHH}$, influences the spatial distribution of the ligand (Briscoe et al. 2001; Chen and Struhl 1996). Similarly, overexpression of Hhip 1 results in a noncell-autonomous induction of Pax7, a gene normally repressed by low levels of $\mathrm{SHH}$ signaling, in abnormal ventral positions. This is consistent with a local depletion of $\mathrm{SHH}$ as a consequence of its sequestration by cells overexpressing Hhip1 (Stamataki et al. 2005). Direct support for the importance of $\mathrm{SHH}$ signaling to limit the extent of $\mathrm{SHH}$ spread comes from analysis of the SHH-GFP allele. In embryos mutant for Smo, which lack the ability to respond to $\mathrm{SHH}$ signaling, SHH-GFP spreads twice as far as in wild-type embryos (Chamberlain et al. 2008). The decay length of the ligand gradient is also extended in the absence of Smo, consistent with a disproportionate expansion of the more ventral domains of gene expression in embryos in which Ptcl and Hhipl gene dosage is reduced (Jeong and McMahon 2005).

The cell-autonomous inhibition of $\mathrm{SHH}$ signaling by Ptcl and Hhip1 also appears important for the cellular interpretation of $\mathrm{SHH}$ signaling in the neural tube. A priori, the transcriptional up-regulation of Ptcl and Hhip 1 by $\mathrm{SHH}$ signaling and their ability to cell-autonomously inhibit $\mathrm{SHH}$ signaling would result in the gradual desensitization of cells to $\mathrm{SHH}$. Consistent with this, the profile

Figure 5. (Continued). The progressive loss of alleles of Hhip1 in the MtPtc1;Ptc1 - / - background exacerbates these phenotypes, demonstrating that Ptcl and Hhip1 share redundant functions in defining the position and precision of boundaries between distinct progenitor domains. (B) Schematic representation of the gradient of $\mathrm{SHH}$ along the DV axis of the neural tube and of the subsequent position of the ventral cell fates in control embryos or in embryos in which Gas1/Cdo/Boc or Ptc1 ${ }^{\Delta l o o p 2}$ have been ectopically expressed (blue shading). The expression of Gas1, Cdo, or Boc results in a local increase in the concentration of SHH protein, thus ventralizing the fate of cells. Because of the local sequestration of the ligand, SHH is reduced dorsally (blue arrow). As a consequence, the size of $\mathrm{pMN}$ and $\mathrm{p} 1$ domains are decreased in size. The expression of $\mathrm{Ptcl}^{\Delta \text { loop2 }}$ leads to a cell-autonomous reduction of the response of cells to SHH. A consequence of this is that cells that would normally adopt a p3 identity are transformed to a more dorsal fate. $\mathrm{Ptcl}^{\Delta \text { loop2 }}$ does not sequester $\mathrm{SHH}$ protein. Therefore, SHH concentration is increased in a noncell-autonomous manner, dorsal to the $\mathrm{Ptcl}^{\Delta \mathrm{loop}^{2}}$ expressing region, which leads to the generation of $\mathrm{p} 3$ cell fate at a position where $\mathrm{pMN}$ is normally generated. 
V. Ribes and J. Briscoe

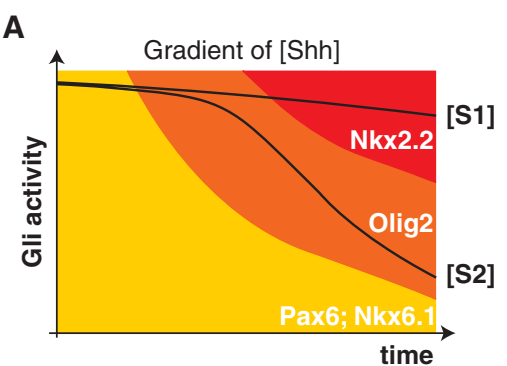

$[\mathbf{S} 1]>[\mathbf{S 2}]$

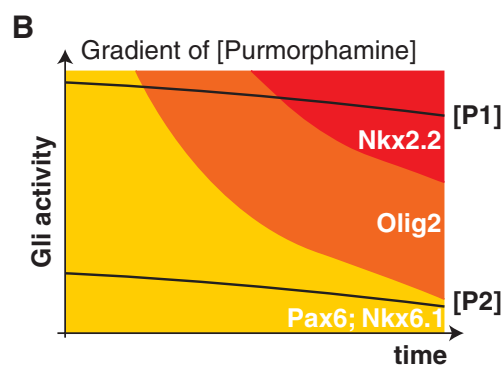

[P1] $>$ [P2]

Figure 6. Correlation between the temporal profiles of Gli activity and gene expression profiles in cells exposed to either SHH or the Smo-agonist purmorphamine. (A) Different concentrations of SHH generate distinct durations of Gli activity. Both low (S1) and high (S2) concentrations of morphogen initially induce high levels of Gli activity. Over time, in cells exposed to a low concentration of $\mathrm{SHH}$, the Gli activity drops quickly, whereas at the high concentration of morphogen, Gli activity is maintained at high levels. Consequently, high concentrations of $\mathrm{SHH}$ induce $\mathrm{Nkx} 2.2$ after transiently expressing Olig2, whereas at the lower concentration, cells maintain Olig2 expression. (B) In contrast to SHH, purmorphamine, a Smo agonist, generates profiles of Gli activity that do not vary as greatly through time. A high concentration (P2) consistently generates higher levels of Gli activity at each time point than a lower concentration (P1). This suggests that the generation of distinct periods of Gli activity by SHH is mediated upstream of Smo.

of Gli activity induced by directly activating Smo using purmorphamine, a small molecule that functions downstream of Ptc1 and Hhip1, is different from that generated by activating the pathway with SHH protein (Dessaud et al. 2007). Although activation by SHH produces periods of Gli activity proportional to the SHH concentration, this is not observed with Smo agonists. This suggests that negative feedback upstream of Smo is required for the normal response of cells (Fig. 6A,B). In addition, inhibition of Ptc1 up-regulation alters the response of cells to defined concentrations of SHH, permitting a lower than normal concentration of SHH to induce more ventral gene expression (Dessaud et al. 2007). This indicates that the SHH dependent up-regulation of Ptcl is necessary for the temporal adaptation of cells to SHH signaling. Together, the data support a model in which the negative feedback loop involving $\mathrm{SHH}$ induction of Ptc1 and Hhip1 plays a crucial role in establishing the normal distribution of $\mathrm{SHH}$ in the neural tube and converting the extracellular concentration of $\mathrm{SHH}$ into an appropriate period of intracellular signaling.

The cell-autonomous and nonautonomous modes of action of Hhip1 and Ptc1 on SHH signaling and their regulation by the pathway constitute a powerful means to generate spatially and temporally restricted patterns of SHH signaling within the target field. The importance of these proteins in the interpretation of graded SHH signaling is illustrated by the progressive increase in the expansion of ventral identities as negative feedback is genetically reduced in mutant mouse embryos (Jeong and McMahon 2005) (Fig. 5A). The relative contribution that the autonomous and nonautonomous mechanisms make to these phenotypes has yet to be assessed and will require methods that provide a way to correlate the distribution of $\mathrm{SHH}$ ligand with ongoing measurements of the activity of the pathway. More generally, these reagents will be important for testing the model of morphogen interpretation and providing a more detailed picture of the dynamics of signaling in the neural tube.

\section{NEGATIVE FEEDBACK AND THE TRANSCRIPTIONAL RESPONSE OF CELLS ARE NECESSARY FOR MORPHOGEN ACTIVITY}

Together, the studies of graded $\mathrm{SHH}$ mediated patterning of the neural tube have revealed the importance of negative feedback in the 
establishment and interpretation of morphogen signaling. On the one hand, this system generates the spatial and temporal dynamics in the cell response to $\mathrm{SHH}$ signaling that are essential for the appropriate gene expression responses. On the other, the opposing roles and activity of Hhip1 and Ptc1, versus Gas1, Cdo, and Boc might act as a buffering system to enhance signaling when levels of $\mathrm{SHH}$ are low and reduce signaling in cells exposed to high levels of ligand. This may compensate for fluctuations in ligand availability, particularly at early stages of neural tube development, thereby rendering some robustness to gradient interpretation (Chamberlain et al. 2008; Jeong and McMahon 2005). The role of inhibitors in providing precision and robustness to morphogen interpretation have been clearly illustrated in Xenopus, where chordin, emanating from the organizer, establishes a well-defined, graded activation profile of BMP signaling (Ben-Zvi et al. 2008). It appears likely that the negative feedback initiated by SHH-binding proteins has a similar precision-enhancing function during patterning of the vertebrate neural tube. In embryos in which negative feedback is disrupted, patterning appears less precise, such that cells belonging to adjacent progenitor domains are extensively intermixed instead of sharply delimited (Allen et al. 2007; Jeong and McMahon 2005) (Fig. 5A). Moreover, just as regulatory feedback involving Chordin is important for scaling the patterns of gene expression to the size of Xenopus embryos, Ptc1- and Hhip1-mediated negative feedback appear important for producing ventral progenitor domains proportioned appropriately to the size of the spinal cord (Allen et al. 2007; Jeong and McMahon 2005; Ben-Zvi et al. 2008).

In addition to the negative feedback relayed by the SHH-binding proteins, the accurate interpretation of $\mathrm{SHH}$ signaling depends on further interactions between the genes that respond to the $\mathrm{SHH}$. Studies are beginning to reveal the gene regulatory network (GRN) operating downstream of SHH-Gli signaling and highlight the importance of the regulatory links within the network for determining the appropriate temporal and spatial gene expression profiles (Briscoe and Ericson 2001; Hallikas et al. 2006; Lei et al. 2006; Ribes et al. 2008; Vokes et al. 2007; Vokes et al. 2008). Two features of the network are almost certainly relevant. First, the Gli proteins appear to directly regulate the expression of several TFs that constitute important functional links within the GRN (Lei et al. 2006; Ribes et al. 2008; Vokes et al. 2007; Vokes et al. 2008). Selective positive and negative cross-regulation between these proteins and other members of the GRN then contribute to the refinement and the maintenance of gene expression profiles (Bailey et al. 2006; Briscoe et al. 2000). Second, Gli proteins are likely to cooperate at the level of cisregulatory elements with other TFs of the GRN (Hallikas et al. 2006; Lei et al. 2006; Ribes et al. 2008), some of which are asymmetrically expressed within the neural tube or activated by other localized signals. This cooperation is an efficient way to create unique combinations of TF activity at distinct locations along the DV axis of the neural tube and thereby increase the diversity of gene responses.

\section{DYNAMIC INTERPRETATION OF MORPHOGEN GRADIENTS}

Significant additional work is needed to provide a comprehensive picture of the molecular mechanisms underlying the response of cells to graded $\mathrm{SHH}$ signaling and the precision in pattern formation in the neural tube. Nevertheless, taken as a whole, the studies of SHH signaling suggest a novel mechanism to explain the response of cells to a morphogen. Cells appear to integrate both extracellular concentrations and durations of the signal to produce discrete durations of intracellular signal transduction. This reconciles models of morphogen activity that have emphasized concentration dependent responses with those that highlight temporal responses (Pages and Kerridge 2000; Jaeger et al. 2008). Importantly, this temporal adaptation mechanism means that positional information, as defined in the French Flag model (Wolpert 1969), cannot be equated solely with a concentration of morphogen. This might also be the case for other morphogens, in 


\section{Ribes and J. Briscoe}

which no direct biochemical correlate of position is immediately apparent in a tissue (Jaeger et al. 2008). Instead, the process of morphogen interpretation is dynamic and one in which a cell constantly refines its response to the signal and in the process of doing so alters the signal itself.

\section{ACKNOWLEDGMENTS}

We are grateful to Anna Kicheva, Eva Kutejova, and Eric Dessaud for critical comments and discussion. V.R. is supported by an EMBO Long Term Fellowship. J.B. is supported by the MRC (UK).

\section{REFERENCES}

Allen BL, Tenzen T, McMahon AP. 2007. The Hedgehogbinding proteins Gasl and Cdo cooperate to positively regulate SHH signaling during mouse development. Genes Dev 21: 1244-1257.

Ashe HL, Briscoe J. 2006. The interpretation of morphogen gradients. Development 133: 385-394.

Aza-Blanc P, Lin HY, Ruiz i Altaba A, Kornberg TB. 2000. Expression of the vertebrate Gli proteins in Drosophila reveals a distribution of activator and repressor activities. Development 127: 4293-4301.

Bai CB, Stephen D, Joyner AL. 2004. All mouse ventral spinal cord patterning by hedgehog is Gli dependent and involves an activator function of Gli3. Dev Cell 6: $103-115$.

Bailey PJ, Klos JM, Andersson E, Karlen M, Kallstrom M, Ponjavic J, Muhr J, Lenhard B, Sandelin A, Ericson J. 2006. A global genomic transcriptional code associated with CNS-expressed genes. Exp Cell Res 312: 3108-3119.

Barnfield PC, Zhang X, Thanabalasingham V, Yoshida M, Hui CC. 2005. Negative regulation of Gli1 and Gli2 activator function by Suppressor of fused through multiple mechanisms. Differentiation 73: 397-405.

Ben-Zvi D, Shilo BZ, Fainsod A, Barkai N. 2008. Scaling of the BMP activation gradient in Xenopus embryos. Nature 453: $1205-1211$.

Bergmann S, Sandler O, Sberro H, Shnider S, Schejter E, Shilo BZ, Barkai N. 2007. Pre-steady-state decoding of the Bicoid morphogen gradient. PLoS Biol 5: e46.

Bergmann S, Tamari Z, Schejter E, Shilo BZ, Barkai N. 2008. Re-examining the stability of the Bicoid morphogen gradient. Cell 132: 15-17; author reply 17-18.

Bollenbach T, Pantazis P, Kicheva A, Bokel C, GonzalezGaitan M, Julicher F. 2008. Precision of the Dpp gradient. Development 135: 1137-1146.

Briscoe J, Chen Y, Jessell TM, Struhl G. 2001. A hedgehoginsensitive form of patched provides evidence for direct long-range morphogen activity of sonic hedgehog in the neural tube. Mol Cell 7: 1279-1291.
Briscoe J, Ericson J. 2001. Specification of neuronal fates in the ventral neural tube. Curr Opin Neurobiol 11: 43-49.

Briscoe J, Pierani A, Jessell TM, Ericson J. 2000. A homeodomain protein code specifies progenitor cell identity and neuronal fate in the ventral neural tube. Cell 101: 435-445.

Chamberlain CE, Jeong J, Guo C, Allen BL, McMahon AP. 2008. Notochord-derived SHH concentrates in close association with the apically positioned basal body in neural target cells and forms a dynamic gradient during neural patterning. Development 135: 1097-1106.

Chen Y, Struhl G. 1996. Dual roles for patched in sequestering and transducing Hedgehog. Cell 87: 553-563.

Chiang C, Litingtung Y, Lee E, Young KE, Corden JL, Westphal H, Beachy PA. 1996. Cyclopia and defective axial patterning in mice lacking Sonic hedgehog gene function. Nature 383: 407-413.

Chuang PT, Kawcak T, McMahon AP. 2003. Feedback control of mammalian Hedgehog signaling by the Hedgehog-binding protein, Hip1, modulates Fgf signaling during branching morphogenesis of the lung. Genes Dev 17: 342-347.

Coulombe J, Traiffort E, Loulier K, Faure H, Ruat M. 2004. Hedgehog interacting protein in the mature brain membrane-associated and soluble forms. Mol Cell Neurosci 25: 323-333.

Dai P, Akimaru H, Tanaka Y, Maekawa T, Nakafuku M, Ishii S. 1999. Sonic Hedgehog-induced activation of the Glil promoter is mediated by GLI3. J Biol Chem 274: 8143-8152.

Danesin C, Agius E, Escalas N, Ai X, Emerson C, Cochard P, Soula C. 2006. Ventral neural progenitors switch toward an oligodendroglial fate in response to increased Sonic hedgehog (SHH) activity: involvement of Sulfatase 1 in modulating SHH signaling in the ventral spinal cord. J Neurosci 26: 5037-5048.

Dessaud E, McMahon AP, Briscoe J. 2008. Pattern formation in the vertebrate neural tube: a sonic hedgehog morphogen-regulated transcriptional network. Development 135: 2489-2503.

Dessaud E, Yang LL, Hill K, Cox B, Ulloa F, Ribeiro A, Mynett A, Novitch BG, Briscoe J. 2007. Interpretation of the sonic hedgehog morphogen gradient by a temporal adaptation mechanism. Nature 450: 717-720.

Ding Q, Motoyama J, Gasca S, Mo R, Sasaki H, Rossant J, Hui CC. 1998. Diminished Sonic hedgehog signaling and lack of floor plate differentiation in Gli2 mutant mice. Development 125: 2533-2543.

Echelard Y, Epstein DJ, St-Jacques B, Shen L, Mohler J, McMahon JA, McMahon AP. 1993. Sonic hedgehog, a member of a family of putative signaling molecules, is implicated in the regulation of CNS polarity. Cell 75: 1417-1430.

Eggenschwiler JT, Anderson KV. 2007. Cilia and developmental signaling. Annu Rev Cell Dev Biol 23: 345-373.

Ericson J, Morton S, Kawakami A, Roelink H, Jessell TM. 1996. Two critical periods of Sonic Hedgehog signaling required for the specification of motor neuron identity. Cell 87: 661-673.

Ericson J, Rashbass P, Schedl A, Brenner-Morton S, Kawakami A, van Heyningen V, Jessell TM, Briscoe J. 
1997. Pax6 controls progenitor cell identity and neuronal fate in response to graded SHH signaling. Cell 90: 169-180.

Freeman M. 2000. Feedback control of intercellular signalling in development. Nature 408: 313-319.

Goodrich LV, Johnson RL, Milenkovic L, McMahon JA, Scott MP. 1996. Conservation of the hedgehog/patched signaling pathway from flies to mice: induction of a mouse patched gene by Hedgehog. Genes Dev 10: 301-312.

Goodrich LV, Milenkovic L, Higgins KM, Scott MP. 1997. Altered neural cell fates and medulloblastoma in mouse patched mutants. Science 277: 1109-1113.

Gregor T, Tank DW, Wieschaus EF, Bialek W. 2007. Probing the limits to positional information. Cell 130: 153-164.

Gritli-Linde A, Lewis P, McMahon AP, Linde A. 2001. The whereabouts of a morphogen: direct evidence for short- and graded long-range activity of hedgehog signaling peptides. Dev Biol 236: 364-386.

Guillemot F. 2007. Spatial and temporal specification of neural fates by transcription factor codes. Development 134: $3771-3780$

Gurdon JB, Bourillot PY. 2001. Morphogen gradient interpretation. Nature 413: 797-803.

Hallikas O, Palin K, Sinjushina N, Rautiainen R, Partanen J, Ukkonen E, Taipale J. 2006. Genome-wide prediction of mammalian enhancers based on analysis of transcription-factor binding affinity. Cell 124: 47-59.

Harfe BD, Scherz PJ, Nissim S, Tian H, McMahon AP, Tabin CJ. 2004. Evidence for an expansion-based temporal SHH gradient in specifying vertebrate digit identities. Cell 118: $517-528$.

Houchmandzadeh B, Wieschaus E, Leibler S. 2002. Establishment of developmental precision and proportions in the early Drosophila embryo. Nature 415: 798-802.

Huang X, Litingtung Y, Chiang C. 2007. Region-specific requirement for cholesterol modification of sonic hedgehog in patterning the telencephalon and spinal cord. Development 134: 2095-2105.

Hynes M, Ye W, Wang K, Stone D, Murone M, Sauvage F, Rosenthal A. 2000. The seven-transmembrane receptor smoothened cell-autonomously induces multiple ventral cell types. Nat Neurosci 3: 41-46.

Ibanes M, Belmonte JC. 2008. Theoretical and experimental approaches to understand morphogen gradients. $\mathrm{Mol}$ Syst Biol 4: 176.

Ingham PW, McMahon AP. 2001. Hedgehog signaling in animal development: paradigms and principles. Genes Dev 15: 3059-3087.

Jacob J, Briscoe J. 2003. Gli proteins and the control of spinal-cord patterning. EMBO Rep 4: 761-765.

Jaeger J, Irons D, Monk N. 2008. Regulative feedback in pattern formation: towards a general relativistic theory of positional information. Development 135: 3175-3183.

Jaeger J, Surkova S, Blagov M, Janssens H, Kosman D, Kozlov KN, Manu Myasnikova E, Vanario-Alonso CE, Samsonova $M$ et al. 2004. Dynamic control of positional information in the early Drosophila embryo. Nature 430: 368-371.

Jeong J, McMahon AP. 2005. Growth and pattern of the mammalian neural tube are governed by partially overlapping feedback activities of the hedgehog antagonists patched 1 and Hhip1. Development 132: 143-154.

Jessell TM. 2000. Neuronal specification in the spinal cord: inductive signals and transcriptional codes. Nat Rev Genet 1: 20-29.

Lee J, Platt KA, Censullo P, Ruiz i Altaba A. 1997. Gli1 is a target of Sonic hedgehog that induces ventral neural tube development. Development 124: 2537-2552.

Lei Q, Jeong Y, Misra K, Li S, Zelman AK, Epstein DJ, Matise MP. 2006. Wnt signaling inhibitors regulate the transcriptional response to morphogenetic SHH-Gli signaling in the neural tube. Dev Cell 11: 325-337.

Lei Q, Zelman AK, Kuang E, Li S, Matise MP. 2004. Transduction of graded Hedgehog signaling by a combination of Gli2 and Gli3 activator functions in the developing spinal cord. Development 131: 3593-3604.

Lupo G, Harris WA, Lewis KE. 2006. Mechanisms of ventral patterning in the vertebrate nervous system. Nat Rev Neurosci 7: 103-114.

Marigo V, Johnson RL, Vortkamp A, Tabin CJ. 1996. Sonic hedgehog differentially regulates expression of GLI and GLI3 during limb development. Dev Biol 180: 273-283.

Marigo V, Tabin CJ. 1996. Regulation of patched by sonic hedgehog in the developing neural tube. Proc Natl Acad Sci 93: 9346-9351.

Marti E, Bumcrot DA, Takada R, McMahon AP. 1995. Requirement of $19 \mathrm{~K}$ form of Sonic hedgehog for induction of distinct ventral cell types in CNS explants. Nature 375: 322-325.

Martinelli DC, Fan CM. 2007. Gas1 extends the range of Hedgehog action by facilitating its signaling. Genes Dev 21: $1231-1243$.

Matise MP, Epstein DJ, Park HL, Platt KA, Joyner AL. 1998. Gli2 is required for induction of floor plate and adjacent cells, but not most ventral neurons in the mouse central nervous system. Development 125: 2759-2770.

Matise MP, Joyner AL. 1999. Gli genes in development and cancer. Oncogene 18: 7852-7859.

Merchant M, Vajdos FF, Ultsch M, Maun HR, Wendt U, Cannon J, Desmarais W, Lazarus RA, de Vos AM, de Sauvage FJ. 2004. Suppressor of fused regulates Gli activity through a dual binding mechanism. Mol Cell Biol 24: 8627-8641.

Milenkovic L, Goodrich LV, Higgins KM, Scott MP. 1999. Mouse patched 1 controls body size determination and limb patterning. Development 126: 4431-4440.

Ochi H, Pearson BJ, Chuang PT, Hammerschmidt M, Westerfield M. 2006. Hhip regulates zebrafish muscle development by both sequestering Hedgehog and modulating localization of Smoothened. Dev Biol 297: 127-140.

Olsen CL, Hsu PP, Glienke J, Rubanyi GM, Brooks AR. 2004. Hedgehog-interacting protein is highly expressed in endothelial cells but down-regulated during angiogenesis and in several human tumors. BMC Cancer 4: 43.

Pages F, Kerridge S. 2000. Morphogen gradients. A question of time or concentration? Trends Genet 16: 40-44.

Pan Y, Bai CB, Joyner AL, Wang B. 2006. Sonic hedgehog signaling regulates Gli2 transcriptional activity by 
V. Ribes and J. Briscoe

suppressing its processing and degradation. Mol Cell Biol 26: $3365-3377$.

Park HL, Bai C, Platt KA, Matise MP, Beeghly A, Hui CC Nakashima M, Joyner AL. 2000. Mouse Glil mutants are viable but have defects in SHH signaling in combination with a Gli2 mutation. Development 127: 1593-1605.

Persson M, Stamataki D, te Welscher P, Andersson E, Bose J Ruther U, Ericson J, Briscoe J. 2002. Dorsal-ventral patterning of the spinal cord requires Gli3 transcriptional repressor activity. Genes Dev 16: 2865-2878.

Pierani A, Brenner-Morton S, Chiang C, Jessell TM. 1999. A sonic hedgehog-independent, retinoid-activated pathway of neurogenesis in the ventral spinal cord. Cell 97: 903-915.

Ribes V, Stutzmann F, Bianchetti L, Guillemot F, Dolle P, Le Roux I. 2008. Combinatorial signalling controls Neurogenin2 expression at the onset of spinal neurogenesis. Dev Biol 321: 470-481.

Roelink H, Porter JA, Chiang C, Tanabe Y, Chang DT, Beachy PA, Jessell TM. 1995. Floor plate and motor neuron induction by different concentrations of the aminoterminal cleavage product of sonic hedgehog autoproteolysis. Cell 81: 445-455.

Rubin JB, Choi Y, Segal RA. 2002. Cerebellar proteoglycans regulate sonic hedgehog responses during development. Development 129: 2223-2232.

Ruiz i Altaba A. 1998. Combinatorial Gli gene function in floor plate and neuronal inductions by Sonic hedgehog. Development 125: 2203-2212.

Scherz PJ, McGlinn E, Nissim S, Tabin CJ. 2007. Extended exposure to Sonic hedgehog is required for patterning the posterior digits of the vertebrate limb. Dev Biol 308: 343-354.

Stamataki D, Ulloa F, Tsoni SV, Mynett A, Briscoe J. 2005. A gradient of Gli activity mediates graded Sonic Hedgehog signaling in the neural tube. Genes Dev 19: 626-641.

Taipale J, Cooper MK, Maiti T, Beachy PA. 2002. Patched acts catalytically to suppress the activity of Smoothened. Nature 418: 892-897.

Tempe D, Casas M, Karaz S, Blanchet-Tournier MF Concordet JP. 2006. Multisite protein kinase A and glycogen synthase kinase 3beta phosphorylation leads to Gli3 ubiquitination by SCFbetaTrCP. Mol Cell Biol 26: 4316-4326.

Tenzen T, Allen BL, Cole F, Kang JS, Krauss RS, McMahon AP. 2006. The cell surface membrane proteins Cdo and
Boc are components and targets of the Hedgehog signaling pathway and feedback network in mice. Dev Cell 10: 647-656.

Varjosalo M, Taipale J. 2008. Hedgehog: functions and mechanisms. Genes Dev 22: 2454-72.

Vokes SA, Ji H, McCuine S, Tenzen T, Giles S, Zhong S, Longabaugh WJ, Davidson EH, Wong WH, McMahon AP. 2007. Genomic characterization of Gli-activator targets in sonic hedgehog-mediated neural patterning. Development 134: 1977-1989.

Vokes SA, Ji H, Wong WH, McMahon AP. 2008. A genome-scale analysis of the cis-regulatory circuitry underlying sonic hedgehog-mediated patterning of the mammalian limb. Genes Dev 22: 2651-2663.

Wang B, Fallon JF, Beachy PA. 2000. Hedgehog-regulated processing of Gli3 produces an anterior/posterior repressor gradient in the developing vertebrate limb. Cell 100: 423-434.

Wijgerde M, McMahon JA, Rule M, McMahon AP. 2002. A direct requirement for Hedgehog signaling for normal specification of all ventral progenitor domains in the presumptive mammalian spinal cord. Genes Dev 16: $2849-2864$.

Wolpert L. 1969. Positional information and the spatial pattern of cellular differentiation. J Theor Biol 25: 1-47.

Woods IG, Talbot WS. 2005. The you gene encodes an EGF-CUB protein essential for Hedgehog signaling in zebrafish. PLoS Biol 3: e66.

Yao S, Lum L, Beachy P. 2006. The ihog cell-surface proteins bind Hedgehog and mediate pathway activation. Cell 125: 343-357.

Zeng X, Goetz JA, Suber LM, Scott WJ Jr, Schreiner CM, Robbins DJ. 2001. A freely diffusible form of Sonic hedgehog mediates long-range signalling. Nature 411: 716-720.

Zhang W, Kang JS, Cole F, Yi MJ, Krauss RS. 2006. Cdo functions at multiple points in the Sonic Hedgehog pathway, and Cdo-deficient mice accurately model human holoprosencephaly. Dev Cell 10: 657-665.

Zhang XM, Ramalho-Santos M, McMahon AP. 2001. Smoothened mutants reveal redundant roles for $\mathrm{SHH}$ and Ihh signaling including regulation of L/R symmetry by the mouse node. Cell 106: 781-792.

Zhuang B, Sockanathan S. 2006. Dorsal-ventral patterning: a view from the top. Curr Opin Neurobiol 16: $20-24$. 


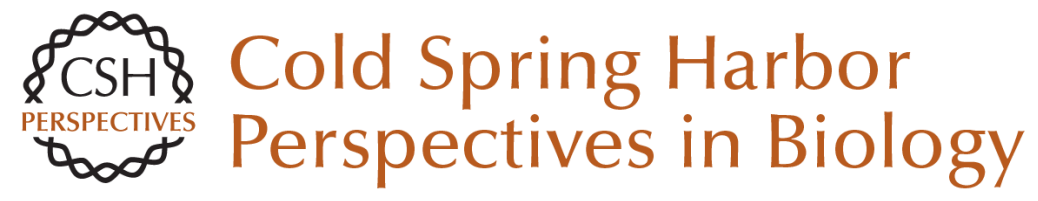

\section{Establishing and Interpreting Graded Sonic Hedgehog Signaling during Vertebrate Neural Tube Patterning: The Role of Negative Feedback}

Vanessa Ribes and James Briscoe

Cold Spring Harb Perspect Biol 2009; doi: 10.1101/cshperspect.a002014 originally published online July 15, 2009

\section{Subject Collection Generation and Interpretation of Morphogen Gradients}

Regulation of Organ Growth by Morphogen

Gradients

Gerald Schwank and Konrad Basler

Signaling Gradients during Paraxial Mesoderm

Development

Alexander Aulehla and Olivier Pourquié

Morphogen Gradient Formation

Ortrud Wartlick, Anna Kicheva and Marcos

González-Gaitán

Nodal Morphogens

Alexander F. Schier

Gradients and the Specification of Planar Polarity in the Insect Cuticle

David Strutt

Vertebrate Limb Development: Moving from Classical Morphogen Gradients to an Integrated 4-Dimensional Patterning System

Jean-Denis Bénazet and Rolf Zeller

Establishing and Interpreting Graded Sonic Hedgehog Signaling during Vertebrate Neural Tube Patterning: The Role of Negative Feedback Vanessa Ribes and James Briscoe
Gradients in Planarian Regeneration and

Homeostasis

Teresa Adell, Francesc Cebrià and Emili Saló

Shaping Morphogen Gradients by Proteoglycans Dong Yan and Xinhua Lin

Forming Patterns in Development without Morphogen Gradients: Scattered Differentiation and Sorting Out

Robert R. Kay and Christopher R.L. Thompson

Robust Generation and Decoding of Morphogen Gradients

Naama Barkai and Ben-Zion Shilo

Models for the Generation and Interpretation of

Gradients

Hans Meinhardt

Graded Dorsal and Differential Gene Regulation in the Drosophila Embryo

Gregory T. Reeves and Angelike Stathopoulos

Chemical Gradients and Chemotropism in Yeast Robert A. Arkowitz

For additional articles in this collection, see http://cshperspectives.cshlp.org/cgi/collection/

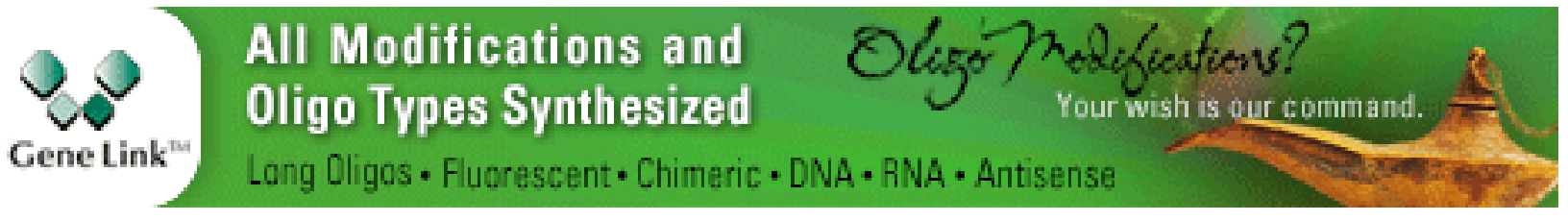


Systems Biology of the Self-regulating

Morphogenetic Gradient of the Xenopus Gastrula Jean-Louis Plouhinec and E. M. De Robertis
Gradients in the Brain: The Control of the Development of Form and Function in the Cerebral Cortex

Stephen N. Sansom and Frederick J. Livesey

For additional articles in this collection, see http://cshperspectives.cshlp.org/cgi/collection/

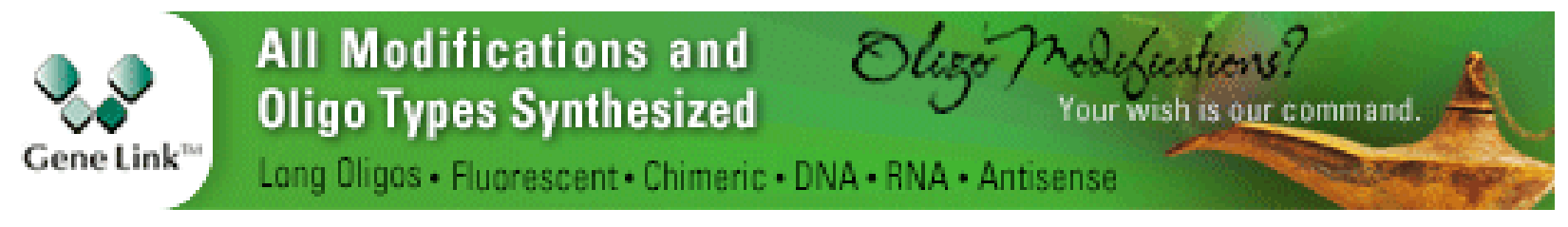

Copyright @ 2009 Cold Spring Harbor Laboratory Press; all rights reserved 